Check for updates

Cite this: RSC Adv., 2018, 8, 32481

\title{
A theoretical study of formaldehyde adsorption and decomposition on a WC (0001) surface $\uparrow$
}

\begin{abstract}
Dandan Wang, ${ }^{\text {ab }}$ Yingying Fan, ${ }^{a}$ Zhonghui Sun, ${ }^{a}$ Dongxue Han (D)*ac and Li Niu ${ }^{\text {ac }}$
A lot of research attention has been paid to designing and exploring efficient adsorbents for $\mathrm{HCHO}$ adsorption and decomposition. Herein, we have demonstrated a highly active material, WC, for $\mathrm{HCHO}$ adsorption through first-principles calculations. Due to the exposed three-coordinated $W$ atoms $\left(W_{3 c}\right)$ of the WC (0001) surface, HCHO molecules can be settled on the WC (0001) surface through newly formed $\mathrm{O}_{F}-W_{3 c}$ and/or $\mathrm{C}_{F}-W_{3 c}$ bonds, forming different adsorption configurations. When settled on the WC (0001) surface, the molecular configuration of the $\mathrm{HCHO}$ molecule and the corresponding $\mathrm{C}_{\mathrm{F}}-\mathrm{H}_{\mathrm{F}}$ and $\mathrm{C}_{F}-\mathrm{O}_{F}$ bond lengths would be greatly changed. Due to the enlarged $\mathrm{C}_{F}-\mathrm{H}_{F}$ and $\mathrm{C}_{F}-\mathrm{O}_{F}$ bond lengths, the adsorbed $\mathrm{HCHO}$ molecules tend to dissociate through two possible pathways; these are the two-step $\mathrm{C}_{F}-\mathrm{H}_{F}$ bond scission or the one-step $\mathrm{C}_{F}-\mathrm{O}_{F}$ bond scission. The former results in two $\mathrm{H}$ adatoms and a $\mathrm{CO}$ molecule chemisorbed to the surface and the latter produces an $\mathrm{O}$ adatom and a $\mathrm{CH}_{2}$ group on the surface. Further $\mathrm{Cl}-\mathrm{NEB}$ calculations demonstrate that the pre-adsorbed $\mathrm{O}$ atom has little influence on the first $\mathrm{C}_{F}-\mathrm{H}_{F}$ bond scission and the $\mathrm{C}_{F}-\mathrm{O}_{F}$ bond scission, while promoting the second $\mathrm{C}_{\mathrm{F}}-\mathrm{H}_{\mathrm{F}}$ bond scission. Considering the dissociative products, $\mathrm{H}$ and $\mathrm{CH}_{2}$ have the potential to couple into a $\mathrm{CH}_{3}$ group (or even a $\mathrm{CH}_{4}$ molecule) and two $\mathrm{CH}_{2}$ groups may couple into a $\mathrm{C}_{2} \mathrm{H}_{4}$ molecule. In the end, we propose that $\mathrm{OH}$ ions may couple with the dissociative products of $\mathrm{HCHO}$, so an alkali solution could be used to post-process the WC (0001) surface to restore its surface active sites. These results demonstrated the potential of $\mathrm{WC}$ in $\mathrm{HCHO}$ sensing and abatement.
\end{abstract}

Received 11th June 2018

Accepted 31st August 2018

DOI: $10.1039 / c 8 r a 04983 a$

rsc.li/rsc-advances

\section{Introduction}

Formaldehyde (HCHO) sensing and detection in both residential and industrial environments has attracted more and more attention because of the damage caused to the human body by this colorless, pungent-smelling gas is enormous. ${ }^{\mathbf{1 - 4}}$ In the past few decades, various technologies for gas detecting have been developed including spectrophotometry, chromatography, polarography and so on. ${ }^{5-9}$ However, the applications in realtime monitoring of indoor volatile organic compounds (VOC) of these technologies have been limited due to the requirements of accurate sample collection, expensive and bulky instrumentation and skilled operators. In recent years, because of their high activity and sensitivity, fast response and easy-operation, a variety of sensing materials, such as supported noble

${ }^{a}$ Center for Advanced Analytical Science, c/o School of Chemistry and Chemical Engineering, Guangzhou University, Guangzhou 510006, P. R. China. E-mail: dxhan@gzhu.edu.cn; Fax: +8643185262800; Tel: +8643185262425

${ }^{b}$ Key Laboratory of Functional Materials Physics and Chemistry of the Ministry of Education, Jilin Normal University, Changchun, 130103, China

'State Key Laboratory of Electroanalytical Chemistry, c/o Engineering Laboratory for Modern Analytical Techniques, Changchun Institute of Applied Chemistry, Chinese Academy of Science, Changchun, 130022, China

$\dagger$ Electronic supplementary information (ESI) available. See DOI: 10.1039/c8ra04983a metals, ${ }^{10-12}$ and metal oxides, ${ }^{13,14}$ have been developed for portable real-time measurement and elimination of HCHO.

Noble metals, especially platinum (Pt), show the most excellent activity for HCHO removal and have attracted a lot of attention. ${ }^{15}$ However, their wide application is hindered by their scarceness and preciousness. Though metal oxides as promising alternatives for $\mathrm{HCHO}$ removal have been extensively studied, ${ }^{\mathbf{1 6}-19}$ most of their performances are unsatisfactory on account of the high reaction temperature. Therefore, it is crucial to develop novel cost-effective adsorbents possessing a good adsorption capacity, large specific surface area and high potential for $\mathrm{HCHO}$ decomposition.

In the early 1970 s, the transition metal carbide, WC has been demonstrated to possess many of the desirable catalytic properties of "noble" metals (such as Pt) with respect to hydrogen oxidation and hydrogenolysis reactions, because its electronic density of states (DOS) near the Fermi level resembles that of Pt. $^{\text {20-22 }}$ Whereafter, considerable attention has been paid to the catalytic properties of transition metal carbide for a variety of reactions. For example, in 1998, MoC and WC have been used as active catalysts for the oxidation of $\mathrm{CH}_{4}$ to synthesis gas. ${ }^{23}$ In recent years, there have been several attempts to apply transition metal carbides as electro catalysts for electrochemical energy conversion devices, such as for $\mathrm{CH}_{3} \mathrm{OH}$ or $\mathrm{H}_{2}$ fuel cells. $^{24,25}$ Transition metal carbide have also been identified as 
a promising catalyst for selective reduction of $\mathrm{CO}_{2}$ by $\mathrm{H}_{2}{ }^{26}$ Recently, their high catalytic activities towards hydrogen evolution reaction (HER) and oxygen reduction reaction (ORR) have been demonstrated. ${ }^{27-30}$

Though their catalytic properties have been widely studied, the activity of transition metal carbides towards $\mathrm{HCHO}$ adsorption and decomposition has never been studied. Whether the transition metal carbides can be used as activation materials for HCHO sensing and elimination? It's well known that when target gases comes in contact with the adsorbents, the adsorption of gas on adsorbents and the electron exchange between them will change the conductivity of the adsorbents. This simple working mechanism indicates that the quality of sensors is determined by the interaction between target gases and sensing materials. What's more, adsorption and decomposition on adsorbents are the most effective elimination mechanism for HCHO removal. Therefore, it is very meaningful to study the adsorption and decomposition behaviors of HCHO towards transition metal carbides for the detecting and removing $\mathrm{HCHO}$ in air.

In this work, we have studied the HCHO adsorption behaviors on the WC (0001) surface by first principles calculations for the first time, which can be took as an example to investigate the catalytic properties of transition metal carbides towards HCHO. Total energy calculation results indicated that the WC (0001) surface exhibits excellent adsorption properties for $\mathrm{HCHO}$ molecules due to the activity of exposed $\mathrm{W}_{3 \mathrm{c}}$ atoms at the surface. The dissociation behavior of $\mathrm{HCHO}$ on clean and O-preadsorbed WC (0001) surface has been characterized. Based on the calculated reaction energy paths, the possible formation mechanisms of $\mathrm{CH}_{3}$ group (or even $\mathrm{CH}_{4}$ ) and $\mathrm{C}_{2} \mathrm{H}_{4}$ are also been presented. $\mathrm{OH}$ ions may be used to couple with the dissociative products of $\mathrm{HCHO}$ on the surface. Those findings in this work may hold the promise for the development of HCHO sensing and elimination.

\section{Computational methods}

We performed DFT calculations within the Perdew-BurkeErnzerhof (PBE) generalized gradient approximation ${ }^{31}$ and the projected augmented wave (PAW) method ${ }^{31-33}$ which was implemented in the Vienna ab initio simulation package (VASP). The cutoff energy for the plane wave basis set is $400 \mathrm{eV}$. Moreover, the convergence threshold was set to be $10^{-4} \mathrm{eV}$ in energy and $10^{-2} \mathrm{eV} \AA^{-1}$ in force for ground state geometry optimizations. The calculated lattice parameters for the hexagonal WC bulk ( $a=b=2.916 \AA, c=2.842 \AA)$ are almost consistent with the experimental values $(a=b=2.906 \AA$, $c=$ $2.837 \AA ̊),{ }^{34}$ suggesting that the calculations may provide $98 \%$ accuracy in describing the geometry structures. According to previous literatures, the most thermodynamically stable surface of WC material is the (0001) surface, ${ }^{35,36}$ and hence the WC (0001) surface is modeled and its performance in HCHO sensing and elimination is investigated. The WC (0001) surface model as shown in Fig. $\mathrm{S} 1 \dagger$ is constructed from the optimized bulk unit cell. Based on our experience and literature reports, a vacuum thickness of $15 \AA$ is adopted in building the periodic slab models to avoid interaction between two adjacent periodic images. ${ }^{37,38}$ And a Monkhorst-Pack of $3 \times 3 \times 1 \mathrm{~K}$-points is applied for the Brillouin-zone integration. For the WC (0001) surface, a supercell slab consisting of eight atomic monolayers including $32 \mathrm{~W}$ atoms and $32 \mathrm{C}$ atoms is constructed and the optimized geometry structure is shown in Fig. S1. $\dagger$

Before adsorption, the isolated HCHO molecule is simulated in a large cubic cell of $15 \AA$ in length and the $\mathrm{O}, \mathrm{C}, \mathrm{H}$ atom of $\mathrm{HCHO}$ are denoted as $\mathrm{O}_{\mathrm{F}}, \mathrm{C}_{\mathrm{F}}, \mathrm{H}_{\mathrm{F}}$ here. For all the adsorption configurations, the atomic positions of the four lower atomic layers are fixed at their bulk geometry and the four upper layers are allowed to fully relax. The adsorption energies are calculated following the equation $E_{\mathrm{ads}}=E_{\mathrm{HCHO}}+E_{\text {surface }}-E_{\mathrm{HCHO} / \text { surface }}$, where $E_{\mathrm{HCHO} / \text { surface }}, E_{\mathrm{HCHO}}$, and $E_{\text {surface }}$ are the total energies of the WC (0001) surface with adsorbed HCHO molecule, the isolated HCHO molecule and the clean WC (0001) surface, respectively. Density of states (DOS), partial density of states (PDOS) and difference charge density are obtained at the optimized geometry structures. Moreover, we have investigated the possible dissociative pathways for adsorbed HCHO molecules, and the coupling pathways of the dissociative products by climbing image nudged elastic band (Cl-NEB) method (finding saddle points and minimum energy paths between known reactants and products).

\section{Results and disscussion}

\subsection{Molecular adsorption of HCHO on WC (0001) surface}

In view of the electronegativity of the $\mathrm{O}_{\mathrm{F}} / \mathrm{C}_{\mathrm{F}}$ atoms and surface $\mathrm{W}$ atoms, new $\mathrm{O}_{\mathrm{F}}-\mathrm{W}$ and/or $\mathrm{C}_{\mathrm{F}}-\mathrm{W}$ bonds may be formed in the adsorption systems. ${ }^{37}$ Moreover, three possible adsorption sites of $\mathrm{O}_{\mathrm{F}} / \mathrm{C}_{\mathrm{F}}$ atoms on the WC (0001) surface as shown in Fig. $\mathrm{S} 1 \dagger$ are selected to compare their adsorption energies. On WC (0001) surface, many various adsorption configurations for $\mathrm{HCHO}$ molecules are considered: $\mathrm{O}_{\mathrm{F}}$ atom of $\mathrm{HCHO}$ molecule on $\mathrm{T} / \mathrm{H} / \mathrm{F}$ site with $\mathrm{HCHO}$ molecule almost parallel/ perpendicular to the surface; $\mathrm{C}_{\mathrm{F}}$ atom of $\mathrm{HCHO}$ molecule on $\mathrm{T} / \mathrm{H} / \mathrm{F}$ site with the symmetrical axis of $\mathrm{HCHO}$ molecule parallel to the surface; $\mathrm{O}_{\mathrm{F}}$ atom of $\mathrm{HCHO}$ molecule on $\mathrm{T} / \mathrm{H} / \mathrm{F}$ site and $\mathrm{C}_{\mathrm{F}}$ on adjacent adsorption sites with the $\mathrm{C}_{\mathrm{F}}-\mathrm{O}_{\mathrm{F}}$ bond almost parallel to the surface.

Through total energy calculations, the stable molecule adsorption configurations for HCHO on the WC (0001) surface are determined and depicted in Fig. 1. As shown in Fig. 1(a), the $\mathrm{O}_{\mathrm{F}}$ atom takes up the $\mathrm{T}$ site and binds to a surface $\mathrm{W}_{3 \mathrm{c}}$ atom with the adsorption energy of $0.70 \mathrm{eV}$, forming a slantwise configuration. The bond length of newly formed $\mathrm{O}_{\mathrm{F}}-\mathrm{W}_{3 \mathrm{c}}$ bond is about $2.13 \AA$. Moreover, the $\mathrm{C}_{\mathrm{F}}-\mathrm{H}_{\mathrm{F}}$ bond of $\mathrm{HCHO}$ is slightly shortened to $1.10 \AA$ ( $0.02 \AA$ shorter) and the $\mathrm{C}_{\mathrm{F}}-\mathrm{O}_{\mathrm{F}}$ bond of HCHO is lengthened to $1.25 \AA 0.04 \AA$ longer than that of isolated $\mathrm{HCHO}$ molecule.

In the configuration shown in Fig. 1(b), HCHO interacts with WC (0001) surface through the $\mathrm{O}_{\mathrm{F}}$ occupying the $\mathrm{T}$ site and bond to one surface $\mathrm{W}_{3 \mathrm{c}}$ atom, meanwhile the $\mathrm{C}_{\mathrm{F}}$ atom taking up the $\mathrm{F}$ site and bond to two surface $\mathrm{W}_{3 \mathrm{c}}$ atoms, in the form of 'hobbyhorse-like' construction. The bond lengths of newly formed $\mathrm{O}_{\mathrm{F}}-\mathrm{W}_{3 \mathrm{c}}$ and $\mathrm{C}_{\mathrm{F}}-\mathrm{W}_{3 \mathrm{c}}$ are $2.00 \AA$ and $2.42 \AA$, respectively 
a

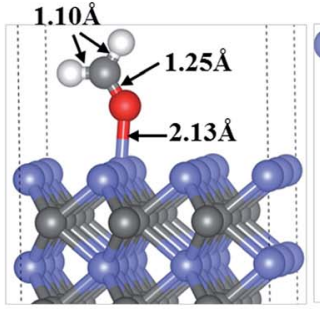

b

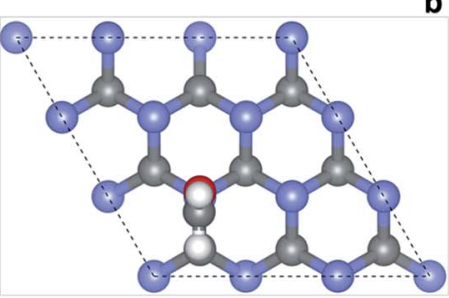

b

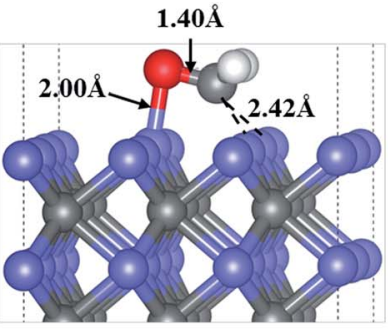

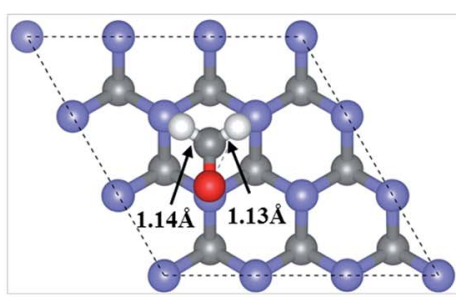

d
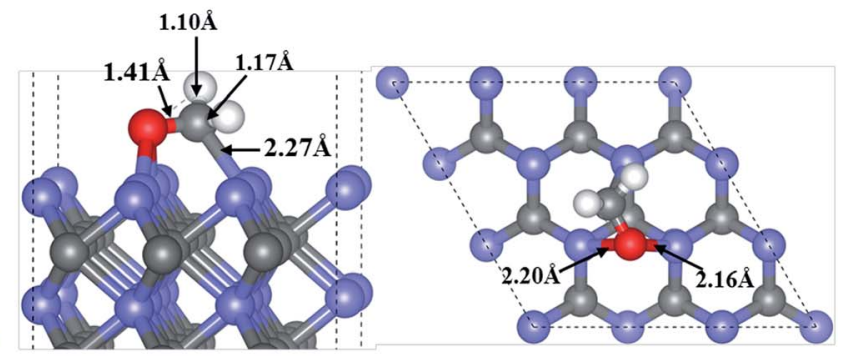

c

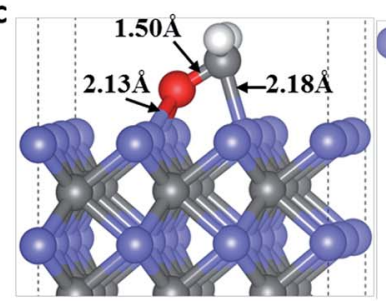

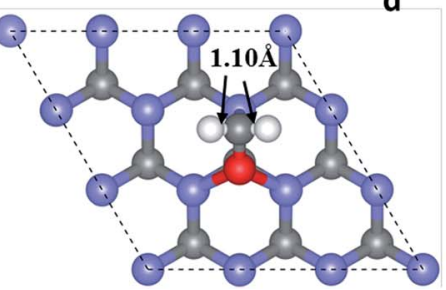

Fig. 1 Side (left) and top (right) views of the optimized structure of molecule adsorption configurations for HCHO molecules on WC (0001) surface. (a) Shows the slantwise adsorption; (b) and (c) and (d) represent the 'hobbyhorse-like' adsorption states. Red, blue, gray and white balls represent $\mathrm{O}$ atoms, $\mathrm{W}$ atoms, $\mathrm{C}$ atoms and $\mathrm{H}$ atoms, respectively.

and the adsorption energy is $1.86 \mathrm{eV}$. Meanwhile, the $\mathrm{C}_{\mathrm{F}}-\mathrm{O}_{\mathrm{F}}$ bond of adsorbed HCHO in this type is lengthened to $1.40 \AA$, $0.19 \AA$ A longer than that of isolated $\mathrm{HCHO}$ molecule. And the $\mathrm{C}_{\mathrm{F}^{-}}$ $\mathrm{H}_{\mathrm{F}}$ bond lengths are also slightly lengthened to $1.13 \AA$ and 1.14 $\AA$, respectively.

HCHO can also chemisorb to WC (0001) surface through two newly formed $\mathrm{O}_{\mathrm{F}}-\mathrm{W}_{3 \mathrm{c}}$ bonds and one newly formed $\mathrm{C}_{\mathrm{F}}-\mathrm{W}_{3 \mathrm{c}}$ bond, as shown in Fig. 1(c) and (d), and the adsorption energies are $1.89 \mathrm{eV}$ and $2.08 \mathrm{eV}$, respectively. These two adsorption configurations also look like 'hobby-horse'. In Fig. 1(c), $\mathrm{O}_{\mathrm{F}}$ and $\mathrm{C}_{\mathrm{F}}$ atoms locate at the $\mathrm{H}$ site and top site, respectively, with newly formed $\mathrm{O}_{\mathrm{F}}-\mathrm{W}_{3 \mathrm{c}}$ and $\mathrm{C}_{\mathrm{F}}-\mathrm{W}_{3 \mathrm{c}}$ bond lengths of $2.13 \AA$ and $2.18 \AA$. And the $\mathrm{C}_{\mathrm{F}}-\mathrm{O}_{\mathrm{F}}$ bond is lengthened to $1.50 \AA$ with the $\mathrm{C}_{\mathrm{F}^{-}}$ $\mathrm{H}_{\mathrm{F}}$ bond lengths shortened to $1.10 \AA$ A. While in Fig. $1(\mathrm{~d})$, the bonding situation is more complicated with two different $\mathrm{O}_{\mathrm{F}^{-}}$ $\mathrm{W}_{3 \mathrm{c}}$ bond lengths $(2.20 \AA$ and $2.16 \AA)$ and the $\mathrm{C}_{\mathrm{F}}-\mathrm{W}_{3 \mathrm{c}}$ bond length is $2.27 \AA$. As well, the $\mathrm{C}_{\mathrm{F}}-\mathrm{O}_{\mathrm{F}}$ bond is lengthened to $1.41 \AA$ while one $\mathrm{C}_{\mathrm{F}}-\mathrm{H}_{\mathrm{F}}$ bond is shortened to $1.10 \AA$ and the other is lengthened to $1.17 \AA$. It is worth noting that the adsorption energies of HCHO on WC (0001) surface are comparable to those for HCHO adsorption on other catalyst surfaces, such as $\mathrm{TiO}_{2}$ (ref. 38) and $\mathrm{WO}_{2.9}$ (ref. 37) surface, indicating that $\mathrm{WC}$ is a suitable catalyst material for HCHO sensing and remove. What's more, $\mathrm{C}_{\mathrm{F}}-\mathrm{O}_{\mathrm{F}}$ bonds of $\mathrm{HCHO}$ are stretched at different levels in different adsorption configurations. This is mainly because the interaction between $\mathrm{O}_{\mathrm{F}} / \mathrm{C}_{\mathrm{F}}$ and surface atoms and newly formed $\mathrm{O}_{\mathrm{F}}-\mathrm{W} / \mathrm{C}_{\mathrm{F}}-\mathrm{W}$ bonds weaken the adjacent $\mathrm{C}_{\mathrm{F}}-\mathrm{O}_{\mathrm{F}}$ bonds. Correspondingly, the interactions between $\mathrm{H}_{\mathrm{F}}$ and $\mathrm{C}_{\mathrm{F}}$ are influenced, leading to shortened or lengthened $\mathrm{C}_{\mathrm{F}}-\mathrm{H}_{\mathrm{F}}$ bonds.

\subsection{Electronic properties of WC (0001) surface with HCHO adsorption}

The electronic structure of WC (0001) surface has been studied by further analysis of total and partial density of states (DOS and
PDOS). As seen from the DOS and PDOS of clean WC (0001) shown in Fig. S2, $\dagger$ the WC (0001) surface is metallic and the density of states near the Fermi level mainly originate from $\mathrm{W}$ atoms, in accordance with previous report, ${ }^{39}$ suggesting that the interaction between the surface and HCHO molecule is primarily the charge transfer between surface $\mathrm{W}$ atoms and HCHO molecule. Therefore, $\mathrm{O}_{\mathrm{F}} / \mathrm{C}_{\mathrm{F}}$ atoms of $\mathrm{HCHO}$ molecules prefer to adsorb on the top site of surface $\mathrm{W}$ atoms, as shown in Fig. 1. Fig. 2 presents the DOS and some atomic PDOS of the HCHO adsorbed WC (0001) surface in stable configurations presented in Fig. 1. To facilitate comparison, the DOS of clean WC (0001) surface is always shown and the Fermi level of WC (0001) surface is assigned at $0 \mathrm{eV}$. Obviously, new electronic states occur at around $-22.5 \mathrm{eV}$ after $\mathrm{HCHO}$ adsorption. The PDOS for the $\mathrm{C}_{\mathrm{F}} / \mathrm{O}_{\mathrm{F}}$ atom and for the corresponding $\mathrm{W}_{3 \mathrm{c}}$ surface atom which is bound to the $\mathrm{C}_{\mathrm{F}} / \mathrm{O}_{\mathrm{F}}$ atom are considered. The PDOS of the $\mathrm{C}_{\mathrm{F}} / \mathrm{O}_{\mathrm{F}}$ atom is broadly dispersed compared with that for HCHO gas-phase (see Fig. S2 $\dagger$ ) and an overlap between $\mathrm{C}_{\mathrm{F}}$ and $\mathrm{W}_{3 \mathrm{c}}$ atom and between $\mathrm{O}_{\mathrm{F}}$ and $\mathrm{W}_{3 \mathrm{c}}$ atom can be clearly seen. The broadening $\mathrm{C}_{\mathrm{F}} / \mathrm{O}_{\mathrm{F}}$ PDOS means the weakened interaction between $\mathrm{C}_{\mathrm{F}}$ and $\mathrm{O}_{\mathrm{F}}$ atom, which is the underlying reason for $\mathrm{C}_{\mathrm{F}}-\mathrm{O}_{\mathrm{F}}$ bond length increase in the adsorption systems. Moreover, the PDOS broadening and overlap indicate the obvious charge redistribution and strong interaction between $\mathrm{C}_{\mathrm{F}} / \mathrm{O}_{\mathrm{F}}$ and surface $\mathrm{W}$ atoms in newly formed bonds of $\mathrm{C}_{\mathrm{F}}-\mathrm{W}_{3 \mathrm{c}}$ and $\mathrm{O}_{\mathrm{F}}-\mathrm{W}_{3 \mathrm{c}}$.

To understand the local charge transfer between the stable adsorbed HCHO molecules and WC (0001) surface, we studied the charge density difference originated from adsorption, as shown in Fig. 3, in which the blue wireframes denote loss of electrons while yellow wireframes denote gain of electrons. Obviously, for the slantwise adsorption state shown in Fig. 1(a), electron only transfers from surface $\mathrm{W}$ atom to the $\mathrm{O}_{\mathrm{F}}$ atom and charges in $\mathrm{HCHO}$ molecule are redistributed, leading to newly formed $\mathrm{O}_{\mathrm{F}}-\mathrm{W}$ bond and extended $\mathrm{C}_{\mathrm{F}}-\mathrm{O}_{\mathrm{F}}$ bond. For adsorption 

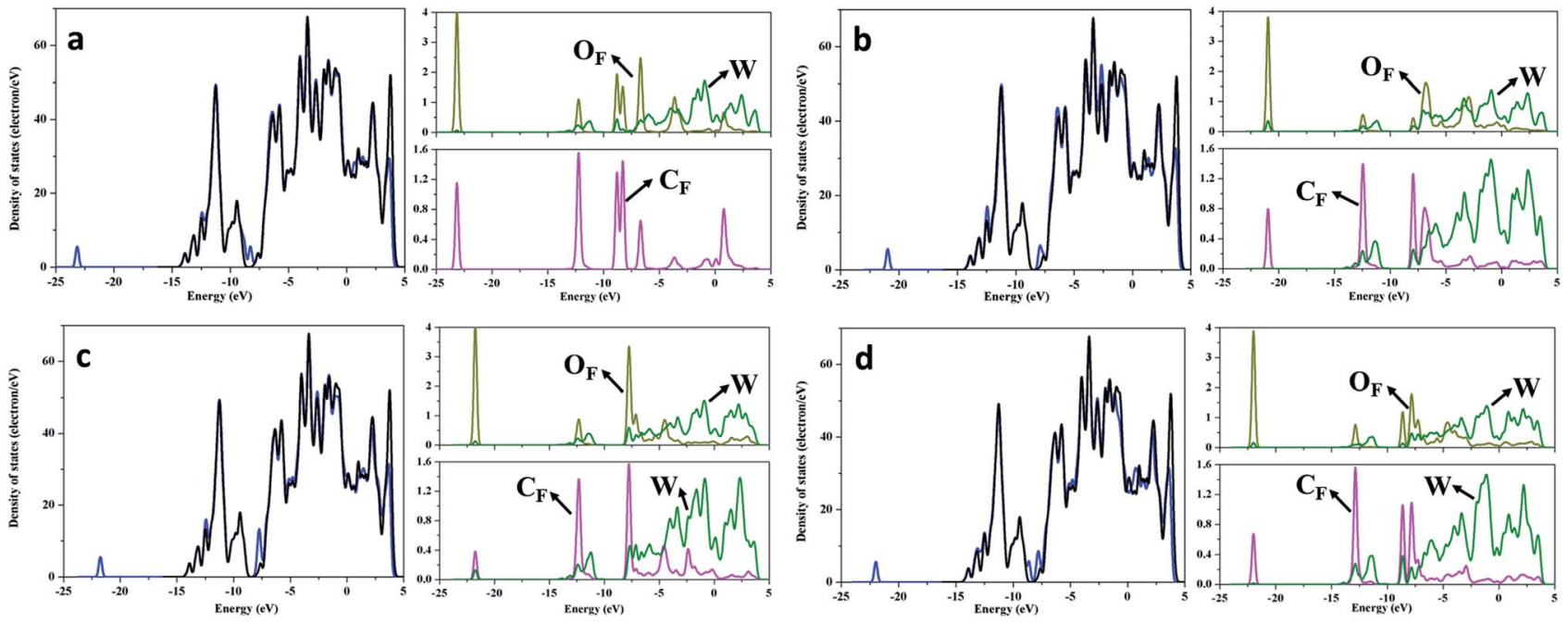

Fig. 2 DOS and PDOS for HCHO adsorbed WC (0001) surface. The curves in (a)-(d) are corresponding to the adsorption configurations shown in Fig. 1(a)-(d), respectively. The black curves present TDOS for WC (0001) surface and TDOS of the clean surface is always plotted to facilitate comparison. The blue curves denote DOS for WC (0001) surfaces with adsorbed $\mathrm{HCHO}$ molecules. PDOS of $\mathrm{C}_{\mathrm{F}}, \mathrm{W}$ and $\mathrm{O}_{\mathrm{F}}$ atoms are denoted by pink, olive and dark yellow curves, respectively. The Fermi level of WC (0001) surface is assigned at $0 \mathrm{eV}$.

a
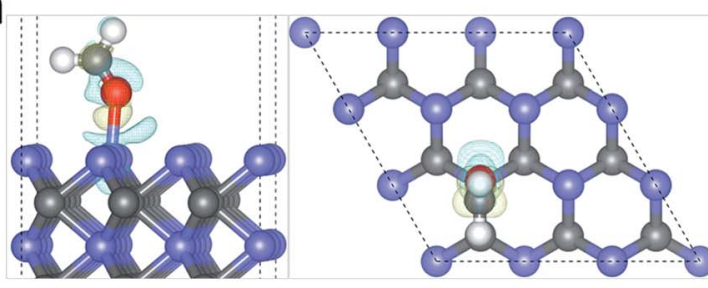

C

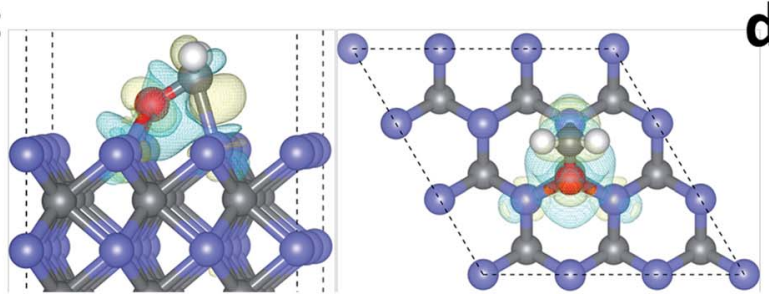

b
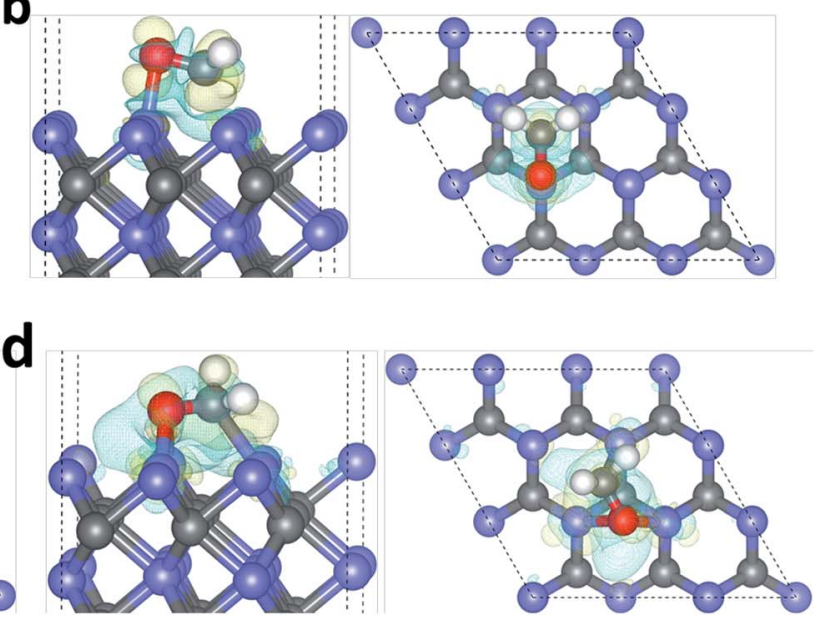

Fig. 3 The isosurface of the difference charge density with the isovalue of $0.003 \AA^{-3}$ and the blue (yellow) wireframes denote loss (gain) of electrons. Red, blue, gray and white balls represent $\mathrm{O}$ atoms, $\mathrm{W}$ atoms, $\mathrm{C}$ atoms and $\mathrm{H}$ atoms, respectively.

configurations shown in Fig. 1(b)-(d), there is obvious charge transfer from the surface $\mathrm{W}_{3 \mathrm{c}}$ atom to $\mathrm{O}_{\mathrm{F}}$ atom and from the $\mathrm{W}_{3 \mathrm{c}}$ atom to $\mathrm{C}_{\mathrm{F}}$ atom as shown in Fig. $3(\mathrm{~b})-(\mathrm{d})$, indicating the strong binding and interaction between HCHO molecules and the WC (0001) surface. Similarly, the charge redistribution occurs in adsorbed HCHO molecules, in accordance with the broadly dispersed PDOS of $\mathrm{C}_{\mathrm{F}}$ and $\mathrm{O}_{\mathrm{F}}$ atoms, which is the cause of the $\mathrm{C}_{\mathrm{F}}-\mathrm{O}_{\mathrm{F}}$ bond increase.

\subsection{Decomposition of HCHO on WC (0001) surface}

To investigate the possibility of HCHO dissociation on WC (0001) surface, we start with the most stable molecule adsorption configuration shown in Fig. 1(d), which means the initial states are the chemisorbed HCHO molecule on WC (0001) surface. Herein, two possible dissociative paths have be considered, namely the two-step $\mathrm{C}_{\mathrm{F}}-\mathrm{H}_{\mathrm{F}}$ bond scission and the one-step $\mathrm{C}_{\mathrm{F}}-\mathrm{O}_{\mathrm{F}}$ bond scission in view of the weakened $\mathrm{C}_{\mathrm{F}}-\mathrm{H}_{\mathrm{F}}$ and $\mathrm{C}_{\mathrm{F}}-\mathrm{O}_{\mathrm{F}}$ bond in adsorbed $\mathrm{HCHO}$ molecule. The product coadsorption configurations with the lowest energies are firstly determined through total energy calculations.

As presented in Fig. 4(a), in the two-step $\mathrm{C}_{\mathrm{F}}-\mathrm{H}_{\mathrm{F}}$ dissociation reaction, the first $\mathrm{C}_{\mathrm{F}}-\mathrm{H}_{\mathrm{F}}$ bond scission products are one $\mathrm{H}$ adatom and one formyl group adsorbed to the surface. The transition states are determined as those structures of saddle points obtained by Cl-NEB method. The minimum energy path for dehydrogenation reaction of $\mathrm{HCHO}$ determined by Cl-NEB method is shown with the overall reaction barrier of only $0.24 \mathrm{eV}$, which is pretty low compared with those reported values and can be easily surmounted. ${ }^{37,40}$ The energy change 
(a)

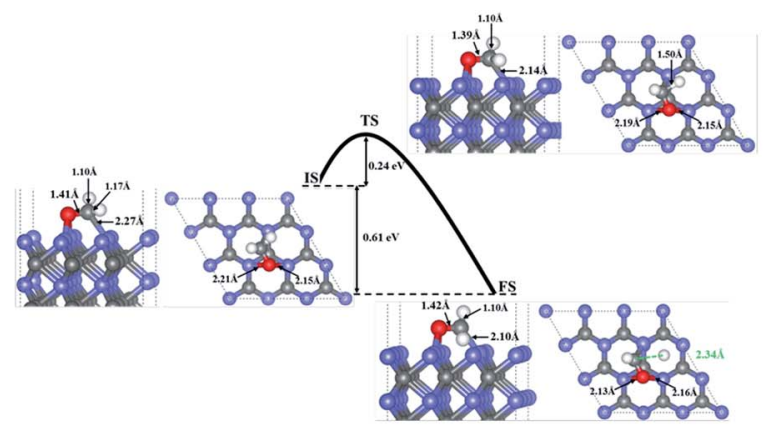

(b)

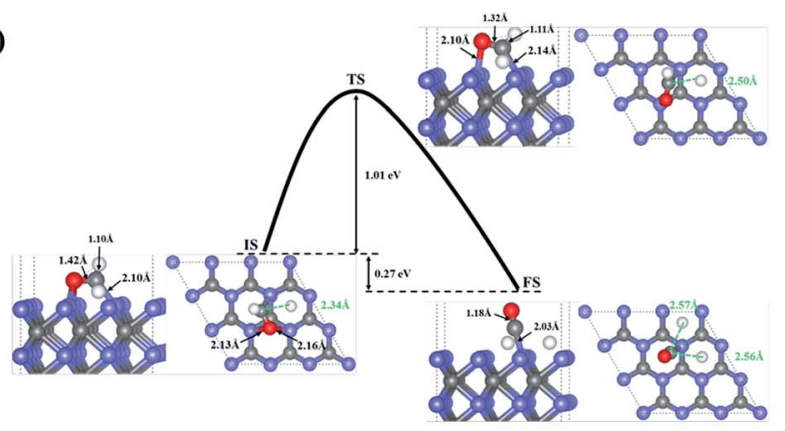

(c)

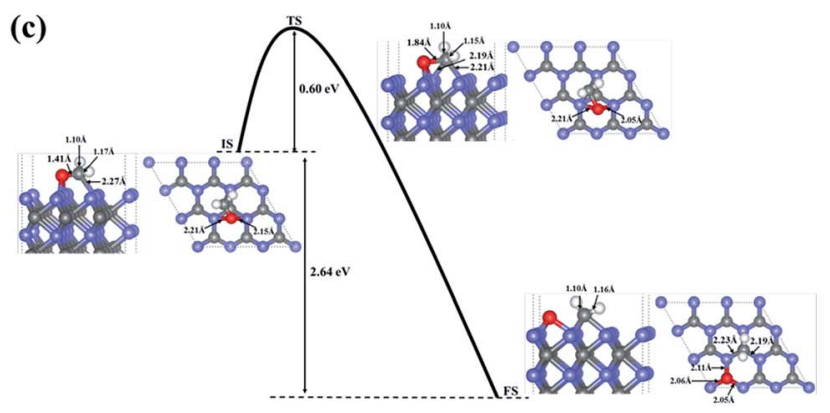

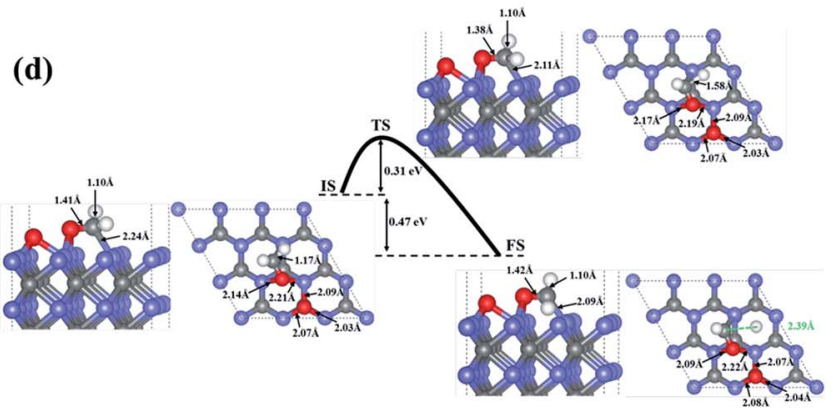

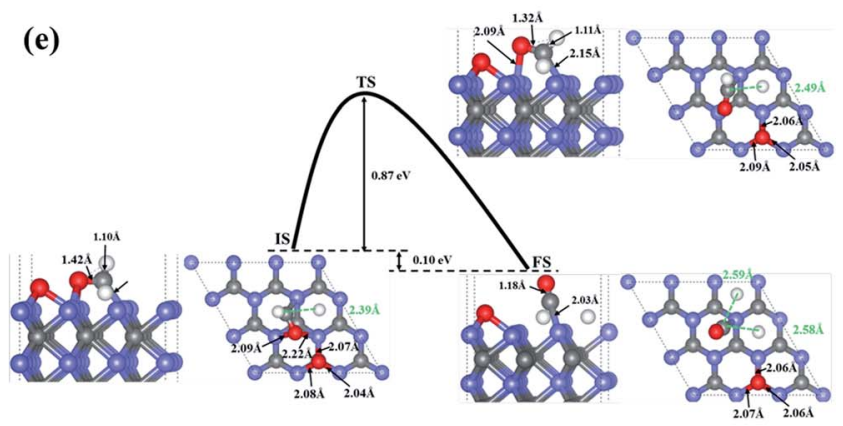

(f)

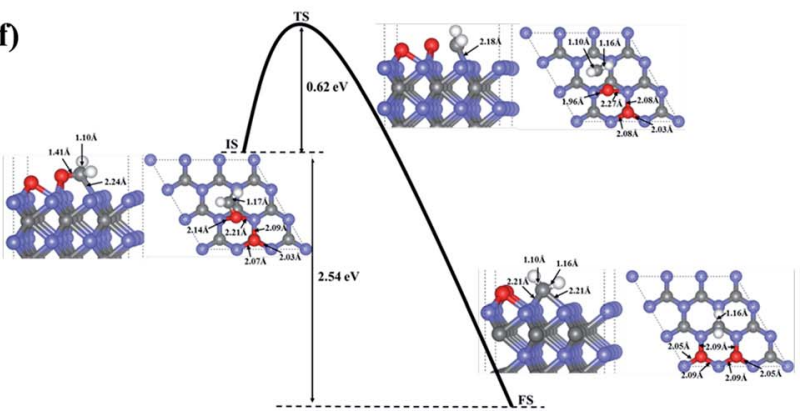

Fig. 4 The minimum energy paths for bond scission reactions of $\mathrm{HCHO}$ molecule adsorbed on the surface in the stable configuration as shown in Fig. 1. (d): (a), (b) and (c) are the first-step $\mathrm{C}-\mathrm{H}$ bond dissociation, second-step $\mathrm{C}-\mathrm{H}$ bond dissociation and the $\mathrm{C}-\mathrm{O}$ bond dissociation on the clean WC (0001) surface; (d), (e) and (f) present the first-step C-H bond dissociation, second-step C-H bond dissociation and the C-O bond dissociation on the O pre-adsorbed WC (0001) surface. Blue, gray and white balls represent $\mathrm{W}$ atoms, $\mathrm{C}$ atoms and $\mathrm{H}$ atoms, respectively.

between the initial and final state is $-0.61 \mathrm{eV}$ (an exothermic process). The bond lengths of $\mathrm{C}_{\mathrm{F}}-\mathrm{O}_{\mathrm{F}}, \mathrm{C}_{\mathrm{F}}-\mathrm{H}_{\mathrm{F}}$ and $\mathrm{O}_{\mathrm{F}}-\mathrm{W}_{3 c}$ bond in the transition state (TS) are quite close to those of the initial state (IS), meaning that the TS is more reactant-like than product-like. After the dehydrogenation reaction, the bond lengths of $\mathrm{C}_{\mathrm{F}}-\mathrm{O}_{\mathrm{F}}$ bonds in $\mathrm{CHO}$ structure are slightly lengthened to $1.42 \AA$, while bond length of one $\mathrm{O}_{\mathrm{F}}-\mathrm{W}_{3 \mathrm{c}}$ bond is shortened to $2.13 \AA$ with the other length almost unchanged. We should note that the $\mathrm{C}_{\mathrm{F}}-\mathrm{W}_{3 \mathrm{c}}$ bond length is obviously shortened by $0.17 \AA$, which means the strengthening of $\mathrm{C}_{\mathrm{F}}-\mathrm{W}_{3 \mathrm{c}}$ bond.

The second $\mathrm{C}_{\mathrm{F}}-\mathrm{H}_{\mathrm{F}}$ bond scission will produce one more $\mathrm{H}$ adatom and a chemisorbed CO molecule towards WC (0001) surface, shown in Fig. 4(b). This dehydrogenation reaction needs to across the transition state with an energy barrier of $1.01 \mathrm{eV}$, and the energy change between the initial and final state is $-0.27 \mathrm{eV}$ (an exothermic process). The bond length of $\mathrm{C}-\mathrm{O}$ bonds in chemisorbed $\mathrm{CO}$ molecule is $1.18 \AA$, and the length of corresponding $\mathrm{C}-\mathrm{W}$ bond between $\mathrm{CO}$ molecule and the surface is $2.03 \AA$. In consideration of the huge gap between the two bond scission barriers, HCHO molecules adsorbed on WC (0001) surface prefer to decompose into $\mathrm{H}$ adatom and $\mathrm{CHO}$ group under mild conditions. Nevertheless, the barrier of $1.01 \mathrm{eV}$ for the second $\mathrm{C}_{\mathrm{F}}-\mathrm{H}_{\mathrm{F}}$ bond scission could be overcomed in some catalytic reactions under combined conditions, such as electrocatalysis and thermocatalysis. ${ }^{40}$

The reaction pathway for the $\mathrm{C}_{\mathrm{F}}-\mathrm{O}_{\mathrm{F}}$ bond scission of adsorbed $\mathrm{HCHO}$ molecule is presented in Fig. $4(\mathrm{c})$. The $\mathrm{C}_{\mathrm{F}}-\mathrm{O}_{\mathrm{F}}$ bond scission is accompanied by a rotation of $\mathrm{C}_{\mathrm{F}}-\mathrm{H}_{\mathrm{F}}$ bonds with the bond length almost unchanged. The reaction needs to across an energy barrier of $0.60 \mathrm{eV}$. Another notable fact is that the reaction is a strong exothermic process and the energy change between the initial and final state is $-2.64 \mathrm{eV}$. The dissociative products, both $\mathrm{CH}_{2}$ and $\mathrm{O}$ adatom, take up the on-top-C sites. Bond lengths of $\mathrm{C}-\mathrm{W}$ bonds between chemisorbed $\mathrm{CH}_{2}$ group and WC (0001) surface are $2.23 \AA$ and $2.19 \AA$, and the lengths of corresponding $\mathrm{O}-\mathrm{W}$ bonds between $\mathrm{O}$ adatom and the surface are $2.05 \AA$, $2.06 \AA$ and $2.11 \AA$. 

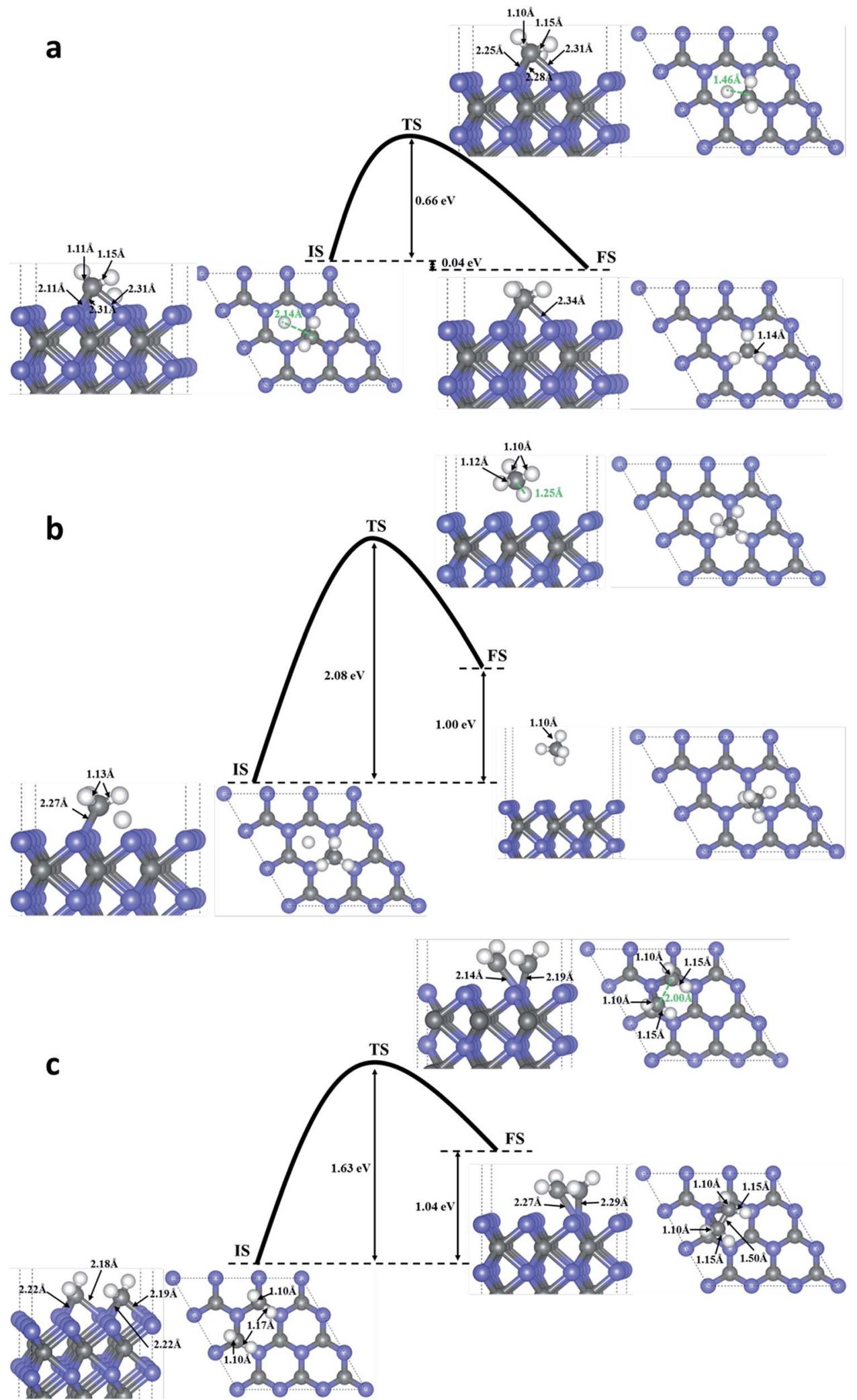

Fig. 5 The minimum energy path for coupling between the products of $\mathrm{H}$ atom and $\mathrm{CH}_{2}$ produced by $\mathrm{HCHO}$ dissociation: (a) $\mathrm{H}$ atom and $\mathrm{CH}$. couple to $\mathrm{CH}_{3}$; (b) $\mathrm{H}$ atom and $\mathrm{CH}_{3}$ couple to $\mathrm{CH}_{4}$; (c) two $\mathrm{CH}_{2}$ combine to $\mathrm{C}_{2} \mathrm{H}_{4}$. Blue, gray and white balls represent $\mathrm{W}$ atoms, $\mathrm{C}$ atoms and $\mathrm{H}$ atoms, respectively. 
Both direct $\mathrm{C}_{\mathrm{F}}-\mathrm{H}_{\mathrm{F}}$ and $\mathrm{C}_{\mathrm{F}}-\mathrm{O}_{\mathrm{F}}$ bond scission processes have small energy barriers and are exothermic, indicating the process are favored on WC (0001) surface and numerous of the dissociation products, $\mathrm{CHO}, \mathrm{CO}, \mathrm{H}, \mathrm{CH}_{2}$, and $\mathrm{O}$ can be produced on the surface. The barrier for the $\mathrm{C}_{\mathrm{F}}-\mathrm{H}_{\mathrm{F}}$ dissociation is slightly lower than that for the $\mathrm{C}_{\mathrm{F}}-\mathrm{O}_{\mathrm{F}}$ dissociation by $0.36 \mathrm{eV}$, meaning that the former is kinetically more favored than the latter, while the latter is thermodynamically more favorable than the former due to larger released energy (2.64 eV vs. 0.61 $\mathrm{eV}$ ). In any case, WC is a suitable catalyst material for $\mathrm{HCHO}$ adsorption and dissociation and $\mathrm{HCHO}$ sensing and remove on WC (0001) surface is quite feasible.

Considering that surface oxygen adatom which stabilizes at the on-top-C site may be active in HCHO adsorption and dissociation reactions, the influence of surface oxygen on $\mathrm{HCHO}$ adsorption and dissociation was studied here. It is found that the surface oxygen adatom wouldn't abstract $\mathrm{H}$ directly from the HCHO molecule. The adsorption configurations and the corresponding adsorption energies of HCHO on WC (0001) surface are almost unaffected by the presence of one $\mathrm{O}$ atom on the surface. What's more, based on total energy calculations, the $\mathrm{H}$ atom originated from the dehydrogenation reaction in the two-step $\mathrm{C}_{\mathrm{F}}-\mathrm{H}_{\mathrm{F}}$ bond scission will occupy a free on-top-C site rather than stick to the pre-adsorbed $\mathrm{O}$ atom (the energy difference between these two states is $1.18 \mathrm{eV}$ ). The energy barrier of the first $\mathrm{C}-\mathrm{H}$ bond dissociation is $0.31 \mathrm{eV}$, which is $0.07 \mathrm{eV}$ higher than that on the clean surface. While the energy barrier of the second $\mathrm{C}-\mathrm{H}$ bond scission is reduced to $0.87 \mathrm{eV}$ (excluding the interaction energy of $0.032 \mathrm{eV}$, which is defined as the difference between the energies of the co-adsorbed configuration and infinite separation state where each surface specie in a separate unit cell at its most stable site) with an energy change between IS and FS of $-0.10 \mathrm{eV}$. The $\mathrm{C}_{\mathrm{F}}-\mathrm{O}_{\mathrm{F}}$ bond scission energy barrier is slightly increased by $0.02 \mathrm{eV}$. Thus, we concluded that the surface adsorbed $\mathrm{O}$ atom will have slight influence on the $\mathrm{C}-\mathrm{H}$ and $\mathrm{C}-\mathrm{O}$ bond breakage of the adsorbed $\mathrm{HCHO}$ molecule, and will promote the decomposition of $\mathrm{CHO}$ to $\mathrm{CO}+\mathrm{H}$. The minimum energy paths of direct $\mathrm{C}_{\mathrm{F}}-\mathrm{H}_{\mathrm{F}}$ and $\mathrm{C}_{\mathrm{F}}-$ $\mathrm{O}_{\mathrm{F}}$ bond scissions on the $\mathrm{O}$ pre-adsorbed surface are shown in Fig. 4(d), (e) and (f), respectively.

We further considered the possible coupling between the products, $\mathrm{H}$ atom and $\mathrm{CH}_{2}$ produced by $\mathrm{HCHO}$ dissociation on WC (0001) surface. Fig. 5(a) indicates that the energy barrier for $\mathrm{H}$ and $\mathrm{CH}_{2}$ coupling to $\mathrm{CH}_{3}$ is $0.66 \mathrm{eV}$ with the energy change of $-0.04 \mathrm{eV}$ (an exothermic reaction). We can speculate that $\mathrm{CH}_{3}$ may further couple with another $\mathrm{H}$ to $\mathrm{CH}_{4}$ with an energy barrier of $2.08 \mathrm{eV}$ and energy change of $1.00 \mathrm{eV}$ (Fig. 5(b)). If an energy barrier of $1.63 \mathrm{eV}$ is overwhelmed, two $\mathrm{CH}_{2}$ would combine into $\mathrm{C}_{2} \mathrm{H}_{4}$ molecule adsorbed on the surface (endothermic by $1.04 \mathrm{eV}$ ) and the reaction path is shown in Fig. 5(b). Moreover, a possible mechanism for recovering the surface active sites could be took into account, i.e. using the alkaline solution to clean the surface. For example, the $\mathrm{CHO}$ can react with the $\mathrm{OH}$ ions in alkaline solution, producing physical adsorbed $\mathrm{H}_{2} \mathrm{O}$ molecule and chemical adsorbed CO molecule on the surface, as shown in Fig. 6(a). The chemical adsorbed CO molecule may react with the $\mathrm{OH}$ ion forming a surface $-\mathrm{COOH}$ (Fig. 6(b)), which would further couple with $\mathrm{OH}$ to physical adsorbed $\mathrm{CO}_{2}$ and $\mathrm{H}_{2} \mathrm{O}$ molecule (Fig. 6(d)). If the $\mathrm{OH}$ attacks the $\mathrm{H}$ atom on the surface, a physical adsorbed $\mathrm{H}_{2} \mathrm{O}$ molecule a

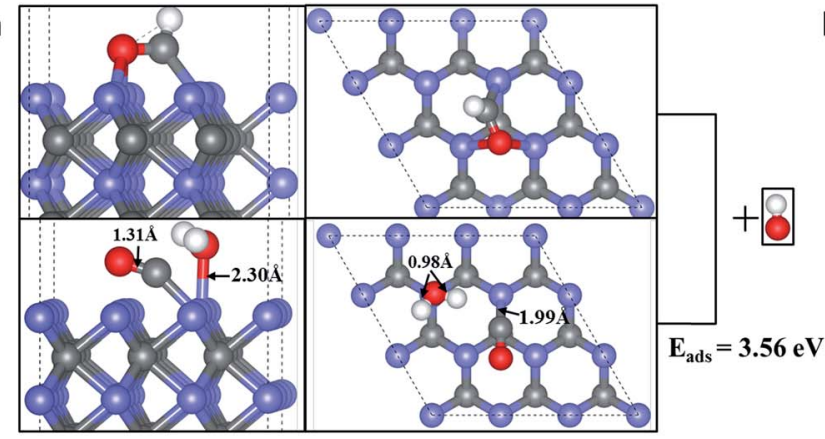

C

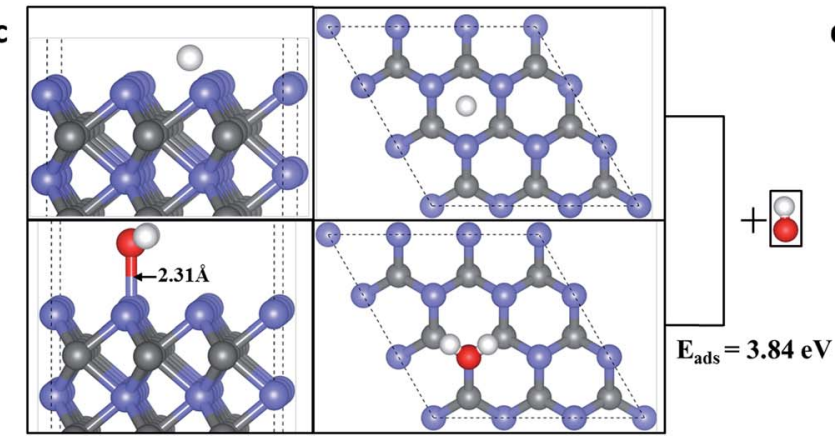

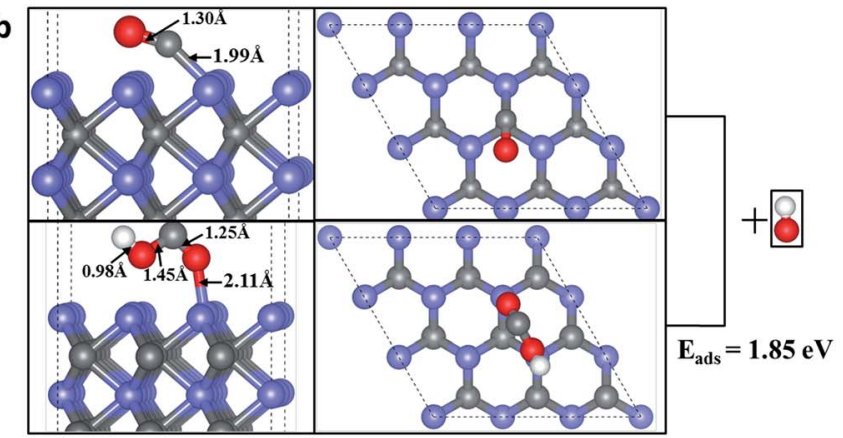

d

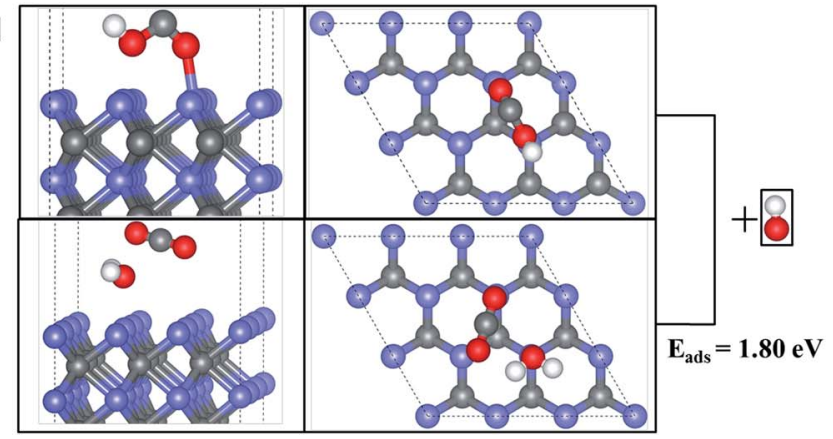

Fig. 6 The adsorption states of $\mathrm{OH}$ towards various surface species (a) $\mathrm{CHO}$, (b) $\mathrm{CO}$, (c) $\mathrm{H}$; (d) $\mathrm{COOH}$. Blue, gray and white balls represent $\mathrm{W}$ atoms, $\mathrm{C}$ atoms and $\mathrm{H}$ atoms, respectively. The adsorption $E_{\text {ads }}$ are defined as the energy difference between the total energy of $\mathrm{CO}+\mathrm{H}_{2} \mathrm{O} /$ $\mathrm{COOH} / \mathrm{H}_{2} \mathrm{O} / \mathrm{CO}_{2}$ on the surface and the sum of the total energy of $\mathrm{CHO} / \mathrm{CO} / \mathrm{H} / \mathrm{COOH}$ on the surface and the energy of isolate OH. 
would be formed (Fig. 6(c)). Those physical adsorbed $\mathrm{CO}_{2}$ and $\mathrm{H}_{2} \mathrm{O}$ molecules may desorb from the surface and the active sites of WC (0001) surface could be recovered. More mechanistic studies for the recovering of the active sites of WC (0001) surface will be investigated in detail in our future work.

\section{Conclusions}

In summary, HCHO adsorption performance on the WC (0001) surface has been systematically investigated based on firstprinciples calculations, indicating that the WC (0001) surface are appropriate for $\mathrm{HCHO}$ sensing and elimination. The calculation results suggest that the exposed $\mathrm{W}_{3 \mathrm{c}}$ atoms at the surface are active for $\mathrm{HCHO}$ adsorption and $\mathrm{HCHO}$ molecules can fasten on the surface mainly in four types through newly formed $\mathrm{O}_{\mathrm{F}}-\mathrm{W}_{3 \mathrm{c}}$ and $\mathrm{C}_{\mathrm{F}}-\mathrm{W}_{3 \mathrm{c}}$ bonds. $\mathrm{HCHO}$ molecules chemisorbed to WC (0001) surface are inclined to decompose across two $\mathrm{C}_{\mathrm{F}}-\mathrm{H}_{\mathrm{F}}$ bond scission steps or one $\mathrm{C}_{\mathrm{F}}-\mathrm{O}_{\mathrm{F}}$ bond scission step, producing $\mathrm{H}$ adatom, $\mathrm{CHO}$ group, $\mathrm{CH}_{2}$ group and $\mathrm{CO}$ molecule chemical adsorbed on the surface. The intermediates, $\mathrm{H}$ adatom and $\mathrm{CH}_{2}$ group, can couple to $\mathrm{CH}_{3}$ (even $\mathrm{CH}_{4}$ ) and $\mathrm{C}_{2} \mathrm{H}_{4}$. Furthermore, $\mathrm{CHO}, \mathrm{H}$ adatom and $\mathrm{CO}$ on the surface can react with $\mathrm{OH}$ ions in alkaline solution, producing physical adsorbed $\mathrm{H}_{2} \mathrm{O}$ and $\mathrm{CO}_{2}$ molecule, which may easily desorb from the surface and the active sites of WC (0001) surface would be recovered for more $\mathrm{HCHO}$ molecules adsorption.

\section{Conflicts of interest}

There are no conflicts to declare.

\section{Acknowledgements}

This work was supported by NSFC, China (21622509, 21475122, 21505127, 21527806, 21627809, 21405147 and 21727815), Department of Science and Techniques of Jilin Province (20160201008GX), Jilin Province Development and Reform Commission (2016C014, 2017C053-1), Science and Technology Bureau of Changchun (15SS05).

\section{References}

1 Y. I. Korpan, M. V. Gonchar, A. A. Sibirny, C. Martelet, A. V. Ela rskaya, T. D. Gibson and A. P. Soldatkin, Biosens. Bioelectron., 2000, 15, 77-83.

2 J.-Y. An, S. Kim, H.-J. Kim and J. Seo, Build. Environ., 2010, 45, 1826-1833.

3 G. McGwin Jr, J. Lienert and J. I. Kennedy Jr, Environ. Health Perspect., 2010, 118, 313.

4 M. Cordiner, A. Remijan, J. Boissier, S. Milam, M. Mumma, S. Charnley, L. Paganini, G. Villanueva, D. BockeléeMorvan, Y.-J. Kuan, et al., Astrophys. Lett., 2014, 792, L2.

5 P. Zhou, D. Zhou, L. Tao, Y. Zhu, W. Xu, S. Xu, S. Cui, L. Xu and H. Song, Light: Sci. Appl., 2014, 3, e209.

6 N. Li, A. Tittl, S. Yue, H. Giessen, C. Song, B. Ding and N. Liu, Light: Sci. Appl., 2014, 3, e226.
7 T. Allsop, R. Arif, R. Neal, K. Kalli, V. Kundrát, A. Rozhin, P. Culverhouse and D. J. Webb, Science, 2015, 16036.

8 J. M. Lorrain, C. R. Fortune and B. Dellinger, Anal. Chem., 1981, 53, 1302-1305.

9 J. C. Septon and J. C. Ku, Am. Ind. Hyg. Assoc. J., 1982, 43, 845852.

10 C. Zhang, H. He and K. Tanaka, Catal. Commun., 2005, 6, 211-214.

11 C. Zhang and H. He, Catal. Today, 2007, 126, 345-350.

12 H. Huang and D. Y. C. Leung, ACS Catal., 2011, 1, 348-354. 13 S. M. Wang, B. X. Xiao, T. Y. Yang, P. Wang, C. H. Xiao, Z. F. Li, R. Zhao and M. Z. Zhang, J. Mater. Chem. A, 2014, 2, 6598-6604.

14 C. Zhang, X. Shi, H. Gao and H. He, J. Environ. Sci., 2005, 17, 429-432.

15 L. H. Nie, J. G. Yu, M. Jaroniec and F. F. Tao, Catal. Sci. Technol., 2016, 6, 3649-3669.

16 S. Lin, D. Li, J. Wu, X. Li and S. Akbar, Sens. Actuators, B, 2011, 156, 505-509.

17 L. Zhang, J. Zhao, H. Lu, L. Gong, L. Li, J. Zheng, H. Li and Z. Zhu, Sens. Actuators, B, 2011, 160, 364-370.

18 Q. Huang, D. Zeng, H. Li and C. Xie, Nanoscale, 2012, 4, 5651-5658.

19 D. D. Wang, D. X. Han, L. Liu and L. Niu, J. Mater. Chem. A, 2017, 4, 14416-14422.

20 R. B. Levy and M. Boudart, Science, 1973, 181, 547-549.

21 L. H. Bennett, J. R. Cuthill, A. J. Mcalister, N. E. Erickson and R. E. Watson, Science, 1974, 184, 563-565.

22 J. E. Houston, G. E. Laramore and R. L. Park, Science, 1974, 185, 258-260.

23 J. B. Claridge, A. P. E. York, A. J. Brungs, C. Marquez-Alvarez, J. Sloan and M. L. H. Green, J. Catal., 1998, 180, 85-100.

24 R. Ganesan and J. S. Lee, Angew. Chem., Int. Ed., 2005, 44, 6557-6560.

25 M. X. Wu, X. Lin, A. Hagfeldt and T. L. Ma, Angew. Chem., Int. Ed., 2011, 50, 3520-3524.

26 M. D. Porosoff, S. Kattel, W. H. Li, P. Liu and J. G. G. Chen, Chem. Commun., 2015, 51, 6988-6991.

27 R. Michalsky, Y.-J. Zhang and A. A. Peterson, ACS Catal., 2014, 4, 1274-1278.

28 Y. N. Regmi, G. R. Waetzig, K. D. Duffee, S. M. Schmuecker, J. M. Thode and B. M. Leonard, J. Mater. Chem. A, 2015, 3, 10085-10091.

29 H. L. Lin, Z. P. Shi, S. He, X. Yu, S. Wang, Q. S. Gao and Y. Tang, Chem. Sci., 2016, 7, 3399-3405.

30 X. Zhang, Z. S. Lu and Z. X. Yang, J. Power Sources, 2016, 321, 163-173.

31 J. P. Perdew, K. Burke and M. Ernzerhof, Phys. Rev. Lett., 1996, 77, 3865.

32 J. Furthmüller, J. Hafner and G. Kresse, Phys. Rev. B: Condens. Matter Mater. Phys., 1994, 50, 15606.

33 G. Kresse and D. Joubert, Phys. Rev. B: Condens. Matter Mater. Phys., 1999, 59, 1758.

34 A. S. Kurlov and A. I. Gusev, Inorg. Mater., 2006, 42, 121-127. 35 Y. Li, Y. Gao, B. Xiao, T. Min, Z. Fan, S. Ma and D. Yi, Comput. Mater. Sci., 2011, 50, 939-948. 
36 D. J. Siegel, L. G. Hector and J. B. Adams, Surf. Sci., 2002, 498, 321-336.

37 D. D. Wang, D. X. Han, L. Liu and L. Niu, J. Mater. Chem. A, 2016, 4, 14416-14422.
38 P. Zhou, X. F. Zhu, J. G. Yu and W. Xiao, ACS Appl. Mater. Interfaces, 2013, 5, 8165-8172.

39 W. F. Zheng, L. T. Chen and C. Ma, Comput. Theor. Chem., 2014, 1039, 75-80.

40 L. M. Liu and J. Zhao, Surf. Sci., 2015, 652, 156-162. 